\title{
Building Resilience in Gender and Sexual Minority Youth
}

\author{
Diane Verrochi, MSN, RN (1)
}

\begin{abstract}
LGBTQ youth are at particularly high risk for various health disparities, many of which are often explained using Meyer's Minority Stress Model (2003). Seminars using peer support strategies are helpful in supporting this age group. This article describes a workshop offered at a conference for LGBTQ youth to empower them to build resilience to the many stresses they will experience as they grow into tomorrow's leaders.
\end{abstract}

Keywords: LGBTQ health; wellness; resilience; minority stress

$\mathbf{R}$ esearch shows that LGBTQ youth are at high risk for various health disparities, many of which are attributed to the concept of minority stress (Institute of Medicine, 2011; Meyer, 2003; Schneeberger, Dietl, Muenzenmaier, Huber, \& Lang, 2014; Williams, Mann, \& Fredrick, 2017). As a nurse who has been teaching and learning about the health issues of LGBTQ people for several years, I often wished for more direct ways to impact the health disparities facing this population. As a member of the LGBTQ community, I had for several years attended an annual conference for LGBTQ youth and providers who support them. I saw an opportunity to offer a workshop for the young people who attended this conference, empowering them to create a wellness tool kit to build resilience, not only to the stresses of everyday life, but the minority stress they experience. The definition of resilience that this workshop uses is "the dynamic process encompassing positive adaptation within the context of significant adversity" (Luthar, Cicchetti, \& Becker, 2000, p. 543).

\section{THE MINORITY STRESS MODEL}

Meyer (2003), building upon prior theories of social stress (Linville, 1987; Thoits, 1991), defined minority stress as "excess stress to which individuals from stigmatized social categories are exposed as a result of their social, often a minority, position" (Meyer, 2003, p. 675). Much of the literature on LGBTQ health has incorporated this model as a way to understand health disparities that do not appear traceable to other biological or social determinants of health (Frost, Lehavot, \& Meyer, 2015; Testa, Habarth, Peta, Balsam,
\& Bockting, 2015). Meyer speaks at some length about tools for coping with the stresses of being part of a minority group, and notes the importance of making connections within the minority group, both to access group-level coping resources and to build one's own personal coping (Meyer, 2003, p. 677). Over the 16 years since the publication of Meyer's seminal article, Meyer (2015) and others have refined the model further and have developed tools to measure minority stress (Testa et al., 2015).

\section{What Knowledge and Tools Already Exist?}

Asakura (2017) noted that LGBTQ youth who showed high resilience tended to be those who took agency in handling the stresses of coming out, of negative behavior from others, and of simply existing in unsupportive environments. The workshop I envisioned focused on promoting exactly that sort of agency. Some support, then, existed for the idea that this intervention could be useful.

Finding support in the literature for the specific tools was more difficult. Chaudoir, Wang, and Pachankis (2017) identified 44 interventions that have been tested with LGB people; only 12 of those interventions focused on increasing resilience. The implication of that imbalance is that most studies focused on making changes to prevent discrimination and stigma from impacting this population in the first place. Of the 12 studies that addressed building resilience, the one most closely related to the proposed workshop was a strengths-based model for multiethnic sexual minority youth (Craig, 2012). 


\section{THE WORKSHOP}

The design of the workshop combined elements of Pender's Theory of Health Promotion (Pender, Murdaugh, \& Parsons, 2011) encouraging participants to reflect on their individual experiences with various forms of stress and coping, recognize the impact of certain behaviors on their affect, and then plan for behavioral outcomes; and Bandura's Self-Efficacy Theory (1977), acknowledging the impact of environmental factors that may or may not be modifiable, and modifying behavioral and personal factors in response. I hoped for synergy between these two theories as participants promoted their own health by increasing their self-efficacy.

The overall approach was extremely simple: Participants identified coping strategies they already used (healthy or not) as well as coping strategies they would like to try (with an emphasis on healthy choices). I taught the group a simple mindfulness tool, a yoga breathing practice known as nadi-shodhana (Singh, Vishaw, \& Parkash, 2011). Then, based on their self-assessment (Figure 1), the participants developed a wellness plan consisting of practices they planned to use regularly, and practices to employ on particularly stressful occasions. Figure 2 is a template for a weekly schedule to help them brainstorm and organize their wellness plans.

The workshop opened with a brief overview of minority stress theory and explained that, especially for those taking leadership roles and working to change the systemic issues causing that stress, it was important to also build resilience to that stress. To underscore that importance and provide the participants with a reminder they could bring home, I included a quote from lesbian poet Audre Lorde on the subject. Once they were introduced to the idea of extra stresses that people may experience because they belong to particular groups, participants often shared anecdotes about ways in which they had experienced this sort of stress. Some expressed outright relief to be able to acknowledge that, yes, they really were under more stress in some

\section{Minority stress is excess stress to which individuals from stigmatized social categories are exposed as a result of their social, often a minority, position.}

ways, and that they might be able to do something about it.

As they wrote their answers to the assessment questions, participants were also encouraged to make a note of anything else they wanted to include, even if it didn't fit the questions. A lesson I learned early was that 5 minutes was the maximum amount of time to give this age group for such a task. In later offerings, I had participants first write down their ideas on large sheets of paper hung around the room, using colorful markers, and then jot down whatever they wanted to keep on the assessment worksheet. This approach gave an outlet for some of their energy while still being on task, and led to much more lively discussion of the different coping mechanisms they could use in different situations, and whether those strategies were likely to actually help (taking a walk, meditating) or not (smoking, drinking alcohol). The level of energy participants brought to the discussion may have been in part because they felt more comfortable sharing their coping mechanisms in writing and semianonymity, and talking about them in more abstract terms.

Once this discussion ran its course, we talked about creating a plan for taking care of their physical, emotional, and spiritual health. The template in Figure 2 included what things they'd like to do during an ideal week, what they might reasonably expect they could do during an average week, and what they could do during a particularly challenging week. The reverse side of this tool contained a grid where they could make notes on the different days of the week about when they might plan to do these things, with a reminder (usually from one of the participants) that the day they have a 2-hour after-school activity would not be the best day to try to squeeze in a yoga class, as one example.

The workshop closed with a discussion of whatever plans they chose to share. Predictably, some were more eager to share than others, but even those who remained quiet often scribbled down notes that may have been ideas gleaned from their more talkative peers. Then, with a reminder that they can always revisit and revise their plan, they left for their next conference sessions.

\section{Responses}

The nature of this intervention dictates that it is not measurable in terms of actual impact on health outcomes. However, participant responses over the past 3 years have been very positive. As with 
De-Stress for Success Self-Assessment

"Caring for myself is not self-indulgence, it is self-preservation, and that is an act of political warfare." - Audre Lorde

Finish as many of the sentences below as you feel comfortable doing. Consider hanging onto them, maybe tucking them into a journal and re-answering them in a few months, as some answers may have changed.

Things you already do

When I feel down, what makes me feel better is

When I've had a bad day at school/work, I

When I feel anxious, what makes me feel better is

When I get to choose what to eat, I have

Physically active things I like to do include

Mentally active things I like to do include

Spiritually active things I like to do include

Things you'd like to try

When I feel down, I'd like to try

When I've had a bad day at school/work, l'd like to try

When I feel anxious, I'd like to try

When I get to choose what to eat, I'd like to try

Physically active things I'd like to try include

Mentally active things l'd like to try include

Spiritually active things I'd like to try include

Reference: Lorde, A. (1988). A Burst of Light, Essays. London: Sheba Feminist Publishers.

Figure 1. De-stress for success self-assessment.

most conferences, anonymous evaluations are completed at the end. Sometimes participants also stop to share their thoughts. Some will say the workshop was fun or that it gave them a different way of thinking about their health. One of the most heart-wrenching responses was from a participant who shared that they chose the workshop about resilience because they had been allowed to attend the conference only on the condition that they didn't attend any workshops that directly addressed LGBTQ issues, but they were glad they

\begin{tabular}{c}
\hline Participants identified coping \\
strategies they already used \\
(healthy or not) as well as coping \\
strategies they would like to try \\
(with an emphasis on healthy \\
choices).
\end{tabular}

attended because they felt they learned something helpful.

\section{IMPLICATIONS FOR PRACTICE}

Regrettably, once participants leave the workshop, I will likely never see them again. When I've shared this curriculum and its worksheets with nurses and other members of the interprofessional team, they have been excited to try some variation of this workshop in their own practice areas, either in group or one-on-one settings. At one professional conference, some critical care nurses spoke of planning to explore this approach not just with their patients, but with patients' family members, as a way of giving them agency in managing the stress of their loved ones' illnesses. A question from a pediatrician in the same group led to all of us helping him brainstorm ways in which a pre-literate child might be encouraged to assess and express what makes them happy, when they feel sad or comfortable, and when they feel afraid. 


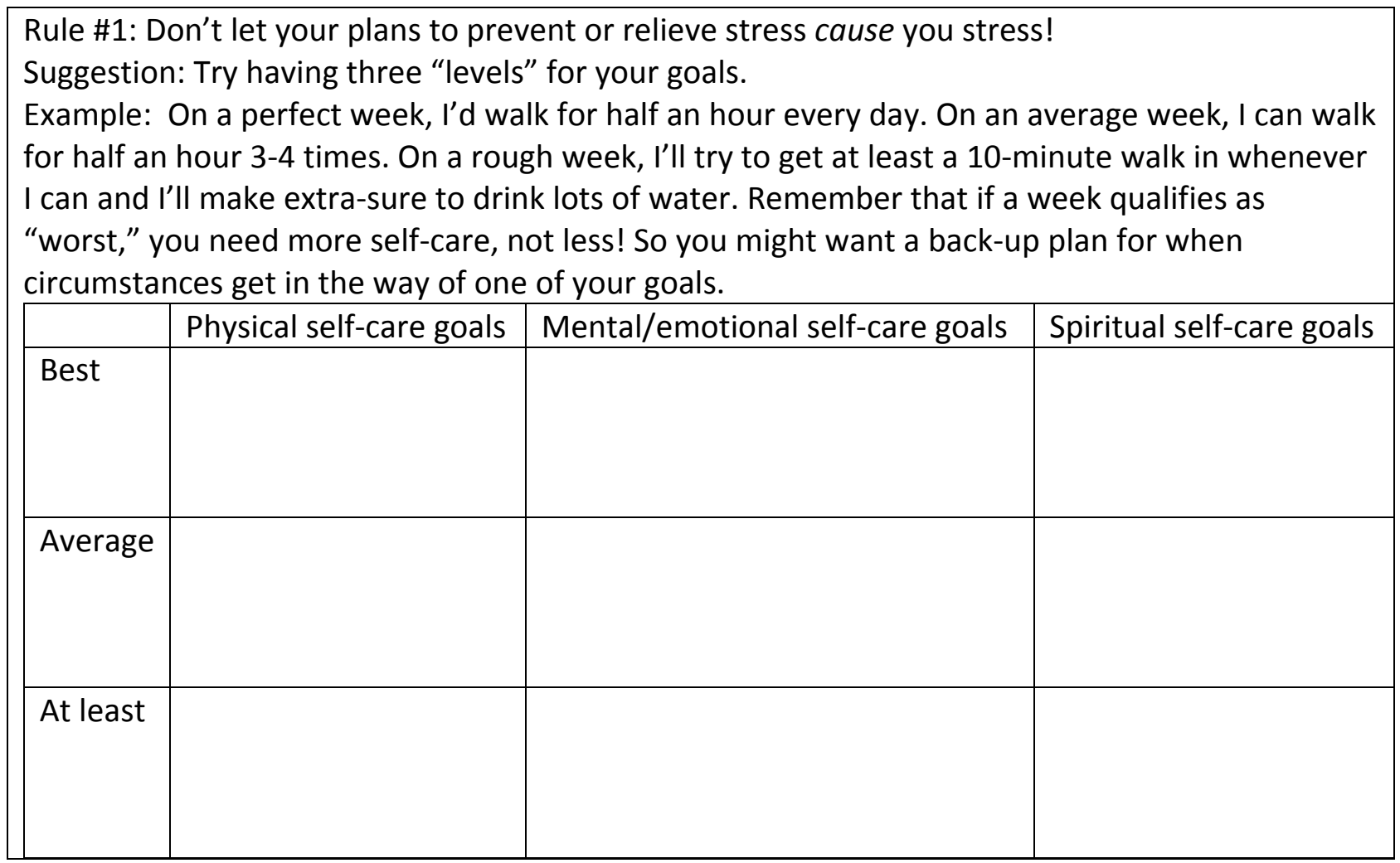

Figure 2. De-stress for success personal wellness plan.

These tools have the potential to be used in a variety of practice areas.

\section{CONCLUSION}

Nurses, whether at the bedside, in an office or clinic, or in a workshop at a youth conference, have many opportunities to both educate and empower their patients. Bearing in mind that those of their patients who are LGBTQ youth are at increased risk for negative health outcomes due to minority stress, nurses can use these or similar tools to help these patients build their own resilience. By centering the patient's existing and desired coping tools, nurses can help their patients to take agency over how this stress impacts them, increasing their self-efficacy as part of promoting health and wellness.

\section{REFERENCES}

Asakura, K. (2017). Paving pathways through the pain: A grounded theory of resilience among lesbian, gay, bisexual, trans, and queer youth. Journal of Research on Adolescence, 27(3), 521-536. https://doi.org/ 10.1111/jora.12291

Bandura, A. (1977). Self-efficacy: Toward a unifying theory of behavioral change. Psychological Review, 84(2), 191-215. https://doi.org/10.1037/0033-295X.84.2.191

Chaudoir, S. R., Wang, K., \& Pachankis, J. E. (2017). What reduces sexual minority stress? A review of the intervention "toolkit." Journal of Social Issues, 73(3), 586-617. https:/ / doi.org/10.1111/josi.12233

Craig, S. L. (2012). Strengths first: An empowering case management model for multiethnic sexual minority youth. Journal of Gay E Lesbian Social Services, 24(3), 274-288. https://doi.org/10.1080/10538720.2012.697833

Frost, D. M., Lehavot, K., \& Meyer, I. H. (2015). Minority stress and physical health among sexual minority individuals. Journal of Behavioral Medicine, 38(1), 1-8. http:/ /dx.doi.org/10.1007/s10865-013-9523-8

Institute of Medicine. (2011). The health of lesbian, gay, bisexual, and transgender people: Building a foundation for better understanding. Washington, DC: National Academies Press. Retrieved from https: / /www.ncbi.nlm.nih.gov / books/NBK64806/

Linville, P. W. (1987). Self-complexity as a cognitive buffer against stress-related illness and depression. Journal of Personality and Social Psychology, 52(4), 663-676. https: / /doi.org/10.1037/0022-3514.52.4.663 
Lorde, A. (1988). A burst of light: Essays. London, England: Sheba Feminist Publishers.

Luthar, S. S., Cicchetti, D., \& Becker, B. (2000). The construct of resilience: A critical evaluation and guidelines for future work. Child Development, 71(3), 543-562. https://doi.org/10.1111/1467-8624.00164

Meyer, I. H. (2003). Prejudice, social stress, and mental health in lesbian, gay, and bisexual populations: Conceptual issues and research evidence. Psychological Bulletin, 129(5), 674-697. https://doi.org/10.1037/ 0033-2909.129.5.674

Meyer, I. H. (2015). Resilience in the study of minority stress and health of sexual and gender minorities. Psychology of Sexual Orientation and Gender Diversity, 2(3), 209-213. http://dx.doi.org/10.1037/sgd0000132

Pender, N. J., Murdaugh, C. L., \& Parsons, M. A. (2011). Health promotion in nursing practice. Upper Saddle River, NJ: Pearson.

Schneeberger, A., Dietl, M., Muenzenmaier, K., Huber, C., \& Lang, U. (2014). Stressful childhood experiences and health outcomes in sexual minority populations: A systematic review. Social Psychiatry \& Psychiatric Epidemiology, 49(9), 1427-1445. https://doi.org/10.1007/ s00127-014-0854-8

Singh, S., Vishaw, G., \& Parkash, V. (2011). Effects of a 6-week nadi-shodhana pranayama training on cardiopulmonary parameters. Journal of Physical Education and Sports Management, 2(4), 44-47.
Testa, R. J., Habarth, J., Peta, J., Balsam, K., \& Bockting, W. (2015). Development of the gender minority stress and resilience measure. Psychology of Sexual Orientation and Gender Diversity, 2(1), 65-77. https://doi.org/10.1037/sgd0000081

Thoits, P. A. (1991). On merging identity theory and stress research. Social Psychology Quarterly, 54(2), 101-112. https: / / doi.org/10.2307/2786929

Williams, S. L., Mann, A. K., \& Fredrick, E. G. (2017). Proximal minority stress, psychosocial resources, and health in sexual minorities. Journal of Social Issues, 73(3), 529-544. https://doi.org/10.1111/josi.12230

Disclosure. The authors have no relevant financial interest or affiliations with any commercial interests related to the subjects discussed within this article.

Funding. The author(s) received no specific grant or financial support for the research, authorship, and/or publication of this article.

Correspondence regarding this article should be directed to Diane Verrochi at dverrochi@hartford.edu

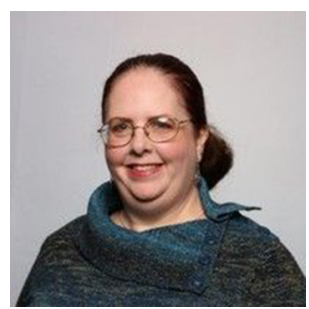

Diane Verrochi, MSN, RN, (she/her/ hers), is an assistant professor of Nursing at the University of Hartford in Hartford, Connecticut. 